\title{
The bearing capacity experimental determination of the keyed joints models in the transport construction
}

\author{
Oksana Dovzhenko ${ }^{1 *}$, Volodymyr Pohribnyi ${ }^{1}$, Ilona Yurko $^{1}$, and Iryna Shostak ${ }^{1}$ \\ ${ }^{1}$ Poltava National Technical Yuri Kondratyuk University, Building Department, Pershotravneviy sq., \\ 24, Poltava, 36011, Ukraine
}

\begin{abstract}
The joints ensure the joint performance of the load carrying structural systems and they are the most responsible and important elements. Keyed joints are widely used in construction. They are characterized by an increased resistance to shear. On these grounds the structural concepts of keyed joints need further improvement. The article presents the research results of experimental test pieces five series in the form of single keys and one-keyed joints. Those samples have been tested in Poltava National Technical Yuriy Kondratyuk University. Follow strength factors have been varied: geometric parameters of joints (depth, height, width) and their ratio; angle of support surface (rectangular, trapezoidal and triangular key); level of compression; reinforcement (quality of reinforcement and the nature of its location); jointing width. The samples were made of heavy-weight, expanded clay and fibre concrete. The experiments program includes influence study both of one of these factors and their combinations. The deformations, nature of failure, the ultimate load have been studied. Structural parameters of keyed joints which ensure the efficient behaviour have been installed.
\end{abstract}

\section{Introduction}

One of the most important elements of the roadway of bridges and overpasses are the keyed joints of their bearing elements. Under significant shear force action keyed joints are the most effective because they have high shearing resistance. Keyed joints are used in the formation of composite sections of precast and cast-in-place and precast constructions (here, as a rule, the contact seam of is used), as well as in the reconstruction of reinforced concrete road bridges. There is a known method of reinforced road bridges widening by means of superimposed slab during the reconstruction. In this case slabs are connected by tension-keyed joint. Thus, keyed joints are widely used in transport construction and they require further detailed study.

The effectiveness of constructive solutions of compounds largely depends on the accuracy of accounting for their design of all factors determining the strength. The carrying capacity of keyed joints is affected by the class and type of concrete, the size of their

\footnotetext{
* Corresponding author: o.o.dovzhenko@gmail.com
} 
reduction and the reinforcement percentage. Researchers have a consensus on the issue of the qualitative nature of the influence of these factors, differing only in quantitative evaluation. What can be said about the dependence of resistance to the destruction of a number of geometric parameters of joints. These include the ratio of the depth of the key to its height, the shape of the profile (the angle of inclination of the loaded face of the key) and the width of the joints. The ambiguity of their accounting leads to unreasonable reserves of carrying capacity and a significant increase in the material intensity of the joints.

In [1-3] is proposed to take into account the shape of the profile of the key way junction in the evaluation of the carrying capacity of connections of concrete and reinforced concrete elements. Increase in the value of the ultimate load of reinforced and crimped trapezoidal and triangular keys in comparison with rectangular ones is established.

However, in $[4,5]$ this factor is neglected. The researchers also do not have a common vision regarding the dependence of the strength of the joint on the width of the joint. The analysis of the studies $[6,7]$ does not introduce unambiguity in the solution of this question. Thus, along with the statement about a significant reduction in the carrying capacity with an increase in the joint width, an opinion is expressed that the effect is not significant. This predetermines the need to obtain new results.

\section{Experimental program}

The code of the first four series samples includes: lettering; the ratio $l_{k} / h_{k}$; the profile shape ( $\mathrm{P}$ - rectangular, $\mathrm{Tr}$ - trapezoidal, $\mathrm{T}$ - triangle $)$; concrete type $(\mathrm{H}$ - heavy, $\mathrm{C}$ - expanded clay, $\mathrm{F}$ - fibre concrete); the level of compression $\sigma / f_{c}$; percentage of reinforcement $\rho_{w} ; 1$ or 2 - the reinforcement location in one or two levels; NT - the presence of friction on the loaded faces (in the remaining samples grip on the abutting surfaces is eliminated). For the fifth series, after the letter designation, the width of the seam is shown.

First series (12 samples were from heavy- concrete and expanded clay concrete) has been investigated to determine the areas of the failure cases implementation of the rectangular concrete keys depending on their sizes ratio $l_{k} / h_{k}[8]$.

The influence of the compression value $\sigma$ on the keys strength at the shear action has been studied during testing the second series (29 samples). In this series height of the keys has been varied within the scope of $h_{k}=50-150 \mathrm{~mm}$, and the depth was constant $l_{k}=50 \mathrm{~mm}$. This led to the change of parameter $l_{k} / h_{k}$ from 0.3 to 1 . The compression value was $\sigma / f_{c}=0-0.47[9]$.

Within the limits of the third series (21 samples made from heavy-weight and expanded clay concrete) the reinforcing effect on the keys strength under shear action has been studied [9]. Samples lateral surfaces have been extended to provide the reliability of bar anchorage. Loading devices were $50 \mathrm{~mm}\left(l_{k}\right)$ lengthwise. That corresponds to the $l_{k} / h_{k}=0.25$ ratio, while the height was $h_{k}=200 \mathrm{~mm}$. In the plane of shear keys have been reinforced. Two types of cages have been used: reinforcement placed in the same level with the middle of the key's height, as well as the two-level placement. The reinforcement ratio has been varied between $\rho_{w}=0-1.03 \%$.

There are single-keyed contact joints (17 samples) with rectangular, trapezoidal and triangular keys with $l_{k} / h_{k}=0.5$ in the fourth series [9]. Support surfaces angle influence on the carrying capacity has been studied. The keyed joints have been reinforced in the plane of the shear in the middle of their height by 2 bars $\varnothing 8, f_{y k}=240 \mathrm{MPa}\left(\rho_{w}=0.67 \%\right)$. Samples with the trapezoidal fibre concrete keys have been tested in order to define the influence of the reinforcement ratio $\rho_{w}=0$ to $2.89 \%$ and the nature of the cross reinforcement placement along the key's height (one or two levels) on the samples strength [10]. 
The fifth series ( 7 samples made from expanded clay and fibre concrete) included single-keyed joints with rectangular keys and variable jointing width $t_{j}=25,50,100,150$ and $200 \mathrm{~mm}$ [9]. The influence of the $t_{j}$ on the ultimate loading and the nature of the joints failure at $l_{k} / h_{k}=0.25-0.5$ was studied.

Both loading schemes moment and no-moment have been implemented during the testing. The load has been transmitted directly to the point of keys or the outer surfaces of the component parts of keyed joints. Manufacturing process of samples and load transmission scheme are described in [9].

\section{Analysis of the results and discussion}

Primarily the nature of failure and maximum load of the keys depend on the ratio of depth $l_{k}$ to height $h_{k}$. When $l_{k} / h_{k}=0.1-0.2$ shearing has been observed under the loading platforms. It has been complemented with the spalling of a part of element along the inclined plane (in other words, shear has been realized on inclined plane). Samples with the $l_{k} / h_{k}=0.3-0.5$ ratio collapsed along the whole concrete section near the shear plane. When $l_{k} / h_{k}=0.6$, failure of the key had flexural nature and was brittle along the tension area (fig. 1).

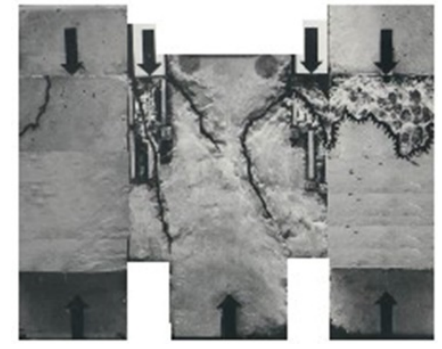

K-0.2-R-C

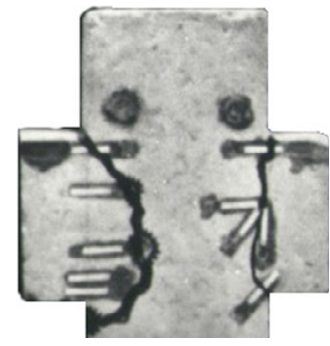

K-0.4-R-C

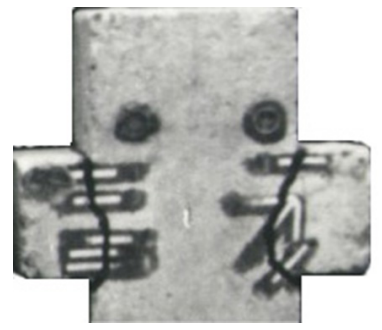

K-0.6-R-C

Fig. 1. The nature of failure of the concrete rectangular keys made from expanded clay concrete depending on $l_{k} / h_{k}$ ratio.

The failure resistance of concrete keyed joints at increasing firstly, and then goes down with the increase of the $l_{k} / h_{k}$ ratio. The strength increases by $25 \%$ when $l_{k} / h_{k}$ ratio is changing from 0.5 to 0.3 . However, the rules $[4,5]$ don't take it into account, although the decline in the influence of the bending moment is obvious. Maximum strength has been obtained: for keyed joints made from expanded clay concrete when the ratio is $l_{k} / h_{k}=0.2$, for keyed joints made from heavy-weight concrete when the ratio is $l_{k} / h_{k}=0.3$ in agreement with the data [11].

Compression of keyed joints $\sigma$ to $0.5 f_{c}$ expands the limits of shear failure to $l_{k} / h_{k}=1$ and prevents the displacement of keys in the horizontal direction (fig. 2). Significant increase of the ultimate load with the growth of compression has been observed [12, 13]. The failure surface of the reinforced concrete samples has been delineated by a curve close to vertical that is due to the accepted ratio $l_{k} / h_{k}=0.5$.

The strength of the samples increased twice with the increase of $\rho_{w}$ to $1.03 \%$. The value of limit load of the keyed joints with two-level reinforcement placement was approximately $10 \%$ higher compared to the keyed joints with central reinforcement placement (see Table 1).

Tests show that single-keyed contact joints (fig. 3) angle of support surface of keys does not change the nature of their failure, but affects the magnitude of the fracture failure.

Keys with the triangular profile have the highest strength, and keys with the rectangular profile - the lowest one. The difference between them is $15 \%$ (see Table 2). 


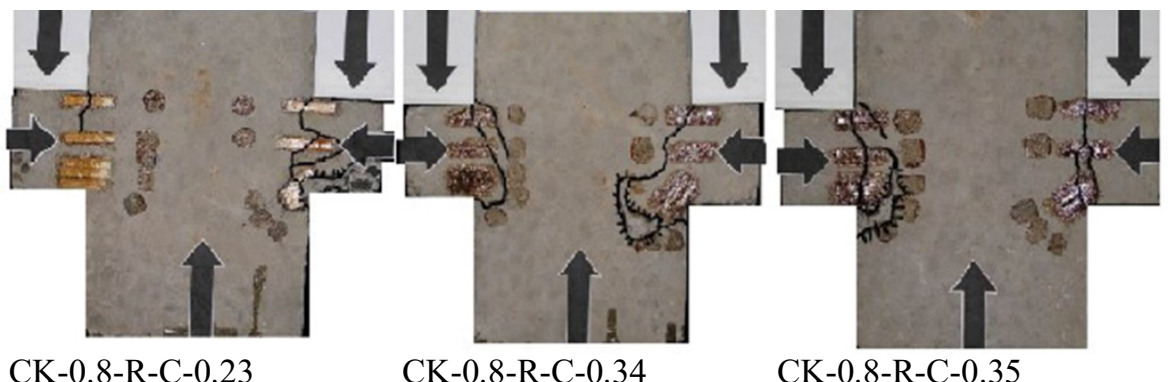

Fig. 2 The nature of failure of the compressed keys made from expanded clay concrete when $l_{k} / h_{k}=0.8$ and $\sigma / f_{c, p r i s m}=0.23-0.35$.

Table 1. Parameters of experimental samples of single keys.

\begin{tabular}{|c|c|c|c|c|c|c|c|}
\hline \multirow{2}{*}{$\begin{array}{c}\text { № } \\
\text { series }\end{array}$} & \multirow{2}{*}{ Samples code } & \multicolumn{2}{|c|}{$\begin{array}{c}\text { Concrete } \\
\text { strength, } \\
\mathrm{MPa}\end{array}$} & \multirow{2}{*}{$\begin{array}{c}\sigma \\
\mathrm{MPa}\end{array}$} & \multicolumn{2}{|c|}{$\begin{array}{l}\text { Cross } \\
\text { reinforcement }\end{array}$} & \multirow{2}{*}{$\begin{array}{l}f_{s h}, \\
\mathrm{MPa}\end{array}$} \\
\hline & & $f_{c}$ & $f_{c t}$ & & amount & $f_{y w}, \mathrm{MPa}$ & \\
\hline \multirow{6}{*}{1} & K-0.2-R-H & \multirow{3}{*}{18.4} & \multirow{3}{*}{1.9} & \multirow{6}{*}{0} & \multirow{22}{*}{-} & \multirow{22}{*}{-} & 2.36 \\
\hline & K-0.4-R-H & & & & & & 4.13 \\
\hline & K-0.6-R-H & & & & & & 2.89 \\
\hline & K-0.2-R-C & \multirow{3}{*}{22.5} & \multirow{3}{*}{1.8} & & & & 4.51 \\
\hline & K-0.4-R-C & & & & & & 3.42 \\
\hline & K-0.6-R-C & & & & & & 2.37 \\
\hline \multirow{16}{*}{2} & CK-0.8-R-C-0.23 & \multirow{5}{*}{23.4} & \multirow{5}{*}{2.3} & \multirow{2}{*}{$\begin{array}{l}5.38 \\
7.96\end{array}$} & & & 5.85 \\
\hline & CK-0.8-R-C-0.34 & & & & & & 7.25 \\
\hline & CK-0.8-R-C-0.35 & & & 8.19 & & & 7.18 \\
\hline & CK-1.0-R-C-0.32 & & & 7.49 & & & 6.36 \\
\hline & CK-1.0-R-C-0.33 & & & 7.72 & & & 7.00 \\
\hline & CK-0.4-R-H-0.09 & \multirow{11}{*}{22.5} & \multirow{11}{*}{2.25} & 2.03 & & & 7.46 \\
\hline & CK-0.4-R-H-0.14 & & & 3.04 & & & 8.66 \\
\hline & CK-0.6-R-H-0.09 & & & 2.03 & & & 5.95 \\
\hline & CK-0.6-R-H-0.18 & & & 4.05 & & & 9.27 \\
\hline & CK-0.6-R-H-0.32 & & & 7.09 & & & 10.32 \\
\hline & CK-0.8-R-H-0.42 & & & 9.55 & & & 7.22 \\
\hline & CK-1.0-R-H-0.29 & & & 6.47 & & & 5.76 \\
\hline & CK-1.0-R-H-0.30 & & & 6.64 & & & 5.53 \\
\hline & CK-1.0-R-H-0.35 & & & 7.79 & & & 6.09 \\
\hline & CK-1.0-R-H-0.41 & & & 9.22 & & & 6.52 \\
\hline & CK-1.0-R-H-0.47 & & & 10.60 & & & 7.51 \\
\hline \multirow{6}{*}{3} & RK-0.25-R-C-0.34-1 & \multirow{6}{*}{23.5} & \multirow{6}{*}{1.51} & \multirow{6}{*}{0} & 208 & 260 & 4.09 \\
\hline & RK-0.25-R-C-0.39-2 & & & & $4 \varnothing 6$ & 280 & 5.30 \\
\hline & RK-0.25-R-C-0.76-1 & & & & $2 \varnothing 12$ & 250 & 6.56 \\
\hline & RK-0.25-R-C-0.67-2 & & & & $4 \varnothing 8$ & 260 & 6.85 \\
\hline & RK-0.25-R-C-1.03-1 & & & & $2 \varnothing 14$ & 240 & 6.86 \\
\hline & RK-0.25-R-C-1.03-2 & & & & $4 \varnothing 10$ & 255 & 7.36 \\
\hline
\end{tabular}


According to the authors, this is due to a change in the trajectory of principal normal compressive stresses as a result of inclination of loaded key verge, the presence of the load horizontal component and reinforcement including into working process on the earlier stages of loading, which leads to the cage effect, and the dominant influence of the cut compared to the break-away (lateral force compared to the bending moment).

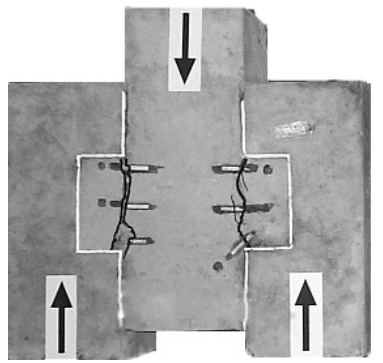

RK-0.5-R-C-0.66-1

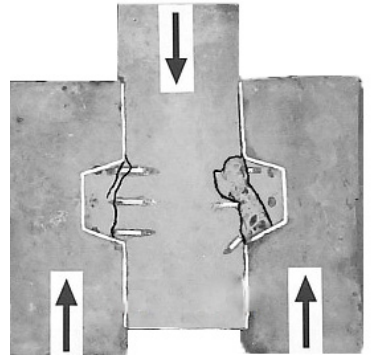

RK-0.5-Tr-C-0.69-1

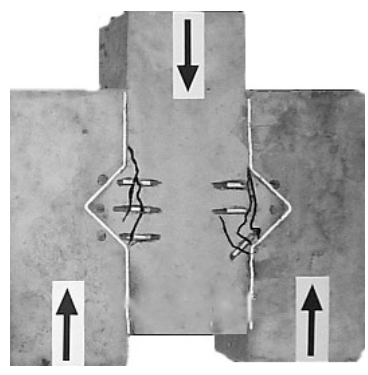

RK-0.5-T-C-0.67-1

Fig 3. The nature of failure of the contact joints made from expanded clay concrete with different key profile.

Table 2. Parameters of experimental samples of one-keyed joints.

\begin{tabular}{|c|c|c|c|c|c|c|c|c|}
\hline \multirow{2}{*}{$\begin{array}{c}\text { № } \\
\text { series }\end{array}$} & \multirow{2}{*}{ Samples code } & \multirow{2}{*}{$\psi,^{\circ}$} & \multicolumn{2}{|c|}{$\begin{array}{c}\text { Concrete } \\
\text { strength, } \\
\mathrm{MPa}\end{array}$} & \multicolumn{2}{|c|}{$\begin{array}{c}\text { Cross } \\
\text { reinforcement }\end{array}$} & \multirow{2}{*}{$\begin{array}{c}t_{j}, \\
\mathrm{~mm}\end{array}$} & \multirow{2}{*}{$\begin{array}{l}f_{s h}, \\
\mathrm{MPa}\end{array}$} \\
\hline & & & $f_{c}$ & $f_{c t}$ & amount & $\begin{array}{l}f_{y w} \\
\mathrm{MPa}\end{array}$ & & \\
\hline \multirow{10}{*}{4} & KJ-0.5-R-C-0.68-1 & \multirow{2}{*}{0} & 16.8 & 1.45 & \multirow{6}{*}{-} & \multirow{6}{*}{-} & \multirow{10}{*}{0} & 4.73 \\
\hline & KJ-0.5-R-C-0.66-1 & & 15.7 & 1.28 & & & & 4.38 \\
\hline & KJ-0.5-Tr-C-0.67-1 & \multirow{2}{*}{17} & 16.8 & 1.45 & & & & 5.0 \\
\hline & KJ-0.5-Tr-C-0.69-1' & & 15.7 & 1.28 & & & & 4.59 \\
\hline & KJ-0.5-T-C-0.69-1 & \multirow{2}{*}{45} & 16.8 & 1.45 & & & & 5.82 \\
\hline & KJ-0.5-T-C-0.67-1' & & 15.7 & 1.28 & & & & 4.97 \\
\hline & KJ-0.5-Tr-F-1.99-2 & \multirow{4}{*}{17} & 12.0 & 1.48 & $4 \varnothing 10$ & 230 & & 4.42 \\
\hline & KJ-0.5-Tr-F-1.81-1 & & 12.0 & 1.48 & $2 \varnothing 14$ & 210 & & 4.95 \\
\hline & KJ-0.5-Tr-F-2.28-1 & & 14.0 & 2.0 & $2 \varnothing 16$ & 220 & & 4.92 \\
\hline & KJ-0.5-Tr-F-2.89-1 & & $\overline{14.0}$ & 2.0 & $2 \varnothing 18$ & 236 & & 5.65 \\
\hline \multirow{7}{*}{5} & KJW-50-0.25-R-C-0.67-1 & \multirow{7}{*}{0} & \multirow{4}{*}{6.4} & \multirow{4}{*}{0.78} & \multirow{7}{*}{$2 \varnothing 8$} & \multirow{4}{*}{240} & 50 & 28.0 \\
\hline & KJW-100-0.25-R-C-0.64-1 & & & & & & 100 & 30.0 \\
\hline & KJW-150-0.25-R-C-0.65-1 & & & & & & 150 & 26.0 \\
\hline & KJW-200-0.25-R-C-0.66-1 & & & & & & 200 & 20.0 \\
\hline & KJW-25-0.5-R-F-0.67-1 & & \multirow{3}{*}{12} & \multirow{3}{*}{1.48} & & \multirow{3}{*}{260} & 25 & 53.0 \\
\hline & KJW-100-0.5-R-F-0.67-1 & & & & & & 100 & 47.0 \\
\hline & KJW-200-0.5-R-F-0.67-1 & & & & & & 200 & 38.0 \\
\hline
\end{tabular}

Statement of the equal strength of triangular and rectangular keyed joints has been connected with the inclusion in the sampling for the comparative analysis of the test results of rectangular keys with a different ratio $l_{k} / h_{k}$, that leads to a significant spread of strength and as a result to a cautious estimate. While changing only the profile of keyed joints the higher strength of triangular keys has been set in comparison with the rectangular keys [1-3]. 
Three cases of failure for single-keyed joints with variable width have been observed (fig. 4): when $t_{j}=25 \mathrm{~mm}$ - keys inclined cracks shear by vertical section has been noticed; when $t_{j}=50 \mathrm{~mm}$ and $t_{j}=100 \mathrm{~mm}$ - keys shear by the inclined plane within the height of the key; when $t_{j}=150 \mathrm{~mm}$ and $t_{j}=200 \mathrm{~mm}$ - inclined cracks that started at the top corner of a key and distributed in space between keys. The key's strength decreases with the increase of joint's width.

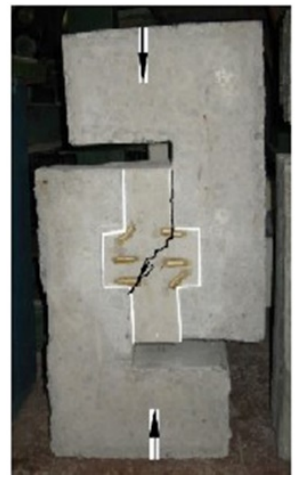

KJR-25-0.5-R-F-0.69-1

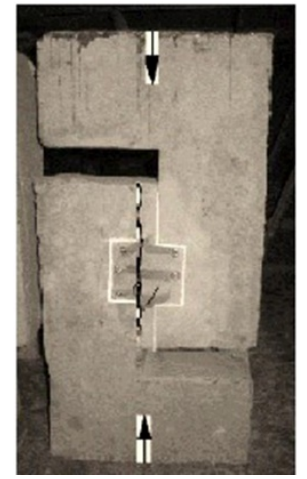

KJR-100-0.5-R-F-0.67-1

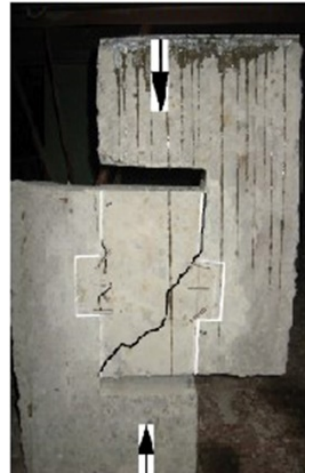

KJR-200-0.5-R-F-0.67-1

Fig. 4. The nature of failure of the single-keyed joints with variable joint's width made from fiber concrete when $l_{k} / h_{k}=0.5$ and $\rho_{w}=0.67 \%$.

Failure surfaces of the concrete, reinforced and compressed keys at the shear action consist of the tensile and compressed areas. Sizes of the last ones rise with the increase of the compression value and the reinforcement ratio. When loads are close to the ultimate ones, concrete deformations reached value of $(180-290) \times 10^{-5}$ in the most compressed areas (in the bottom incoming corners of the key). Moreover, maximum deformations were noticed in samples with higher compression level, reinforcement ratio and spaced-apart reinforcement.

Analysis of studies results of different types of keyed joints has been made on the basis of the evaluation of influence of separate factors and it allowed to explain a number of existing different interpretations of influence assessment of ratio of keys $l_{k} / h_{k}$, the width of the seam $t_{j}$, the profile shape on keyed joints strength.

Experimental assessment of the strength of keyed joints research and data from other studies [1-3, 6, 7, 11-13] found theoretical substantiations and corroboration of [14], which are based on vibrational methods, the concept of a rigid body and the principle of virtual velocities.

\section{Conclusions}

The obtained data allow to make the following conclusions:

1. Ultimate load value and the nature of failure of the concrete keys (crushing, shear, tear, failure) depend on ratio of their sizes in the key plane. For maximum joint strength it is recommended to admit $l_{k} / h_{k}=0.25$ ratio.

2. Compression and reinforcing significantly increase keyed joint's strength (up to 2.5 times), spread shear limits of the failure form (till $l_{k} / h_{k}=1$ ) and increase concrete plastic properties.

3. Two-level reinforcement placement along the key's height increase jointing strength to $10 \%$ and deformations of the concrete compressive zone - to $50 \%$. The dowel effect appears in the bottom reinforcing rods. 
4. Keys with the triangular profile have maximum strength at $l_{k} / h_{k}=0.5(15 \%$ comparing with the rectangular keys).

5. The sharp increase of the concrete and reinforcement deformations was noticed. Also plastic constituent of the deformation was noticed in the phase before shear failure of the joint. At $\rho_{w} \leq 1 \%$ reinforcement stress reach the yield point at the moment of failure.

6. The use of the fiber reinforced concrete for the joint's grouting increases crack resistance and strength of the joints, and changes the nature of failure from brittle to plastic.

7. Concrete keys are recommended to design with a rectangular profile with a ratio of depth to height $0.2 \leq l_{k} / h_{k} \leq 0.5$, reinforced concrete and compressed - trapezoidal with the ratio $l_{k} / h_{k}$ in the above range and triangular with $l_{k} / h_{k}=0.5$. This ratio may to be increased to value 1 when compression value is $\sigma / f_{c}=0.4$ or percentage transverse reinforcement is $\left.\rho_{w}=1 \%\right)$. Reinforcement in the range of $1 \%$ can be considered effective.

\section{References}

1. Y. Naotaka, T. Norimono, K. Katori, S. Hayashi, Struct. Constr. Eng., Japan, 10(1), 441-442, (1997)

2. S.I. Izni, H.P. Khairul, H. Mansoor, A. Bady, A.A. Saim, N.N. Sarbini, Malaysian Journal of Civil Engineering, 26(3), 414-430, (2014)

3. Ch.H. Lee, W.J. Chin, E.S. Choi, Y.J. Kiml, Journal of the Korea Concrete Institute, 23(2), 235-244, (2011)

4. Design of Concrete Structures - Part 1: General rules and rules for buildings, EN 1992-1-1: Eurocode 2, Brussels, (2007)

5. Betonni ta zalizobetonni konstruktsii z vazhkogo betonu. Pravila proyektuvannya, DSTU B V.2.6-156: 2010, National Standard of Ukraine, (2011)

6. G.N. Ashkinadze, M.E. Sokolov, L.D. Martynova, Zhelezobetonnyye steny seysmostoykikh zdaniy. Issledovaniye i osnovy proyektirovaniya, Moscow, (1988)

7. I.A. Gerasimova, Beton i zhelezobeton, Moscow, 4, 72-76, (1987)

8. V.V. Pogrebnoy, Prochnost' betonnykh i zhelezobetonnykh elementov pri sreze, Ph.D thesis in Engineering science, Poltava, (2000)

9. O.O. Dovzhenko, Mitsnist' shponkovykh z'yednan' betonnykh $i$ zalizobetonnykh elementiv: eksperymental'ni doslidzhennya, Poltava, (2012)

10. I.A Yurko, Mitsnist' shponkovykh stykiv iz fibrobetonu na osnovi syntetychnykh volokon, Ph.D thesis in Engineering science, Poltava, (2012)

11. A.V. Yashin, Beton i zhelezobeton, Moscow, 6, 17-18, (1978)

12. G. Rombach, Technical University Hamburg, Germany, 2, 56-60, (2002)

13. S.H. Rizkalla, R.L. Serette, J.S. Heuvel, E.K. Attiogbe, PCI Journal, 3-4, 104-120, (1989)

14. O.O. Dovzhenko, V.V. Pohribnyi, Y.V. Chursa, Bulletin of the National University "Lviv Polytechnic", Lviv, 755, 111-117, (2013) 